\title{
Talus Fractures in Children Associated with Ipsilateral Bone Injuries
}

\begin{abstract}
N. K. Sferopoulos
Department of Pediatric Orthopaedics, "G. Gennimatas" Hospital, Thessaloniki, Greece

*Corresponding Author: N. K. Sferopoulos, Department of Pediatric Orthopaedics, "G. Gennimatas" Hospital,Thessaloniki,Greece.E-mail:sferopoulos@in.gr, sferopoulos@yahoo.com

Abstract: Fractures of the talus are very rare in children. The most common talar fracture involves the neck. A history of a fall with axial loading of the ankle, followed by pain and swelling in the area of the ankle, should conduct the clinical examination towards a talus fracture. With high-energy trauma, such as falls from height, crushing and lawnmower injuries, clinical deformity, displacement as well as a large degree of soft tissue damage may be evident. In addition, ipsilateral fractures in the foot or tibia, the so called floating ankle', may also be encountered. It should be emphasized that it is only the careful clinical examination that will alert the trauma surgeon whenever an area of tenderness is revealed in a neighboring area where a secondary traumatic bone lesion may exist. Treatment of talar fractures in younger children is more often conservative with generally good results, whereas talar fractures in older children are best addressed like fractures in adults. Avascular necrosis is the main cause of disability following fractures of the talus in children and may be followed by early degenerative changes. The incidence of avascular necrosis following talus fractures in children is considerably higher in high-energy injuries, especially in those associated with concomitant fractures, as well as in initially missed, and therefore non-treated, fractures.
\end{abstract}

Keywords: Talus, children, ipsilateral, concomitant, tibia, foot, fractures

\section{EDITORIAL}

The talus is divided anatomically into the body, the neck, and the head. The head of the talus articulates with the navicular bone and is mostly cartilaginous. Little cartilage is present on the neck, which is largely an area of vascular perforation. There are no direct muscular attachments on the talus. Because much of the talar surface is made up of articular cartilage, it has limited vascular connections and a precarious blood supply that can be directly affected by fracture. The four main sources of extraosseous blood supply are branches of the posterior tibial, anterior tibial, and peroneal arteries. The sinus tarsi is the entry for most of the blood supply of both the talus and the calcaneus.

The rare incidence of pediatric fractures of the foot has precluded large epidemiologic series referring to outcomes and rates of complications. However, the incidence is becoming higher due to the increasing participation of children in high-impact sports and in recreational activities of greater intensity and physical contact than ever before, and even in competing extreme sports (motocross, all terrain vehicles, motorized dirt bike or snowmobile racing, rock-climbing, etc).

The usual mechanisms of talus fractures are forceful dorsiflexion of the foot in a fall from a height or twisting trauma combining a component of supination with the forced dorsiflexion and axial loading. Crushing injuries to the foot (as by an automobile or motorbike tire) and lawnmower injuries may result in severe leg injuries.

The skeletally immature bones of a very young child's developing foot is much more flexible and resilient to traumatic forces and may lead to patterns of injuries different from those seen in adults.

Talar fractures in children may be classified in type I-IV fracture patterns correlating with the severity of injury and the risk of avascular necrosis using the Hawkins classification, modified by Canale and Kelly that is used in adults. Fractures of the body of the talus were initially classified in 1977 into transchondral 
dome fractures, lateral process or posterior tubercle fractures and shear or crush fractures. A classification, including two groups of patients, depending on the age of the injured child has also been proposed. In children younger than 6 years the diagnosis may be easily missed because the fracture may not be clearly delineated on radiographs. In children older than 6 years osteochondral fractures, complete fractures and avascular necrosis are more commonly encountered.

History and clinical examination in children with fractures of the talus may be challenging. The child is usually unable to bear weight on the affected extremity. Physical examination reveals a painful effusion of the anterior aspect of the ankle joint. In undisplaced injuries, the presentation may be subtle and the injury may be easily missed. With high-energy trauma, such as falls from height and traffic road accidents, a large degree of soft tissue damage and clinical deformity is often evident, while concomitant fractures elsewhere in the foot or about the ankle may also be encountered (Fig. 1, $2)$. The injured foot must be examined for vascular viability and for any sensory deficits, as well as for signs and symptoms of foot compartment syndrome. It has been shown that compartment syndrome of the foot in children may occur with soft tissue damage alone, without an obvious fracture.

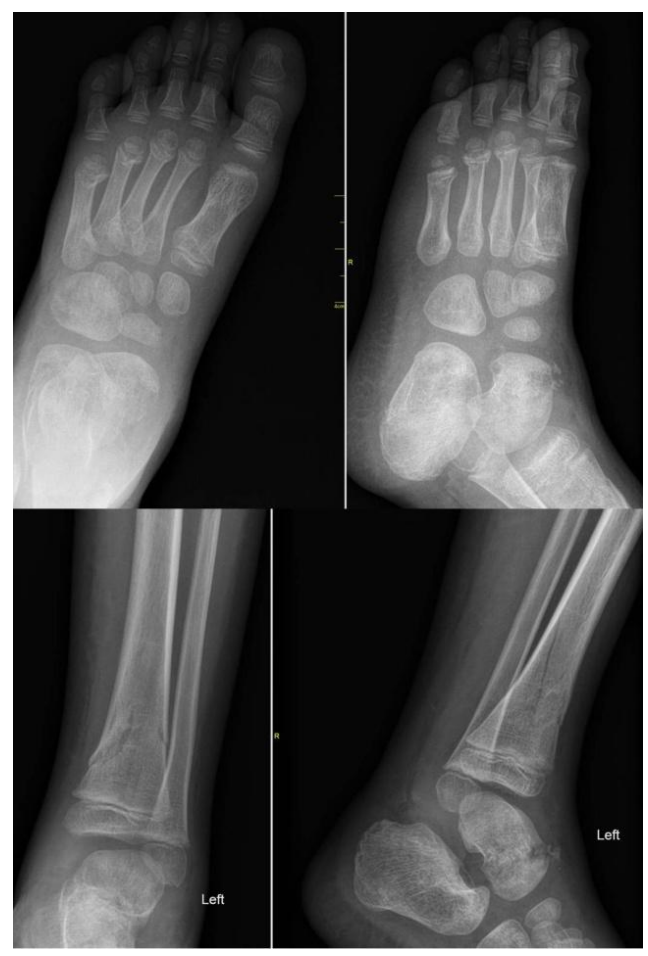

Figure 1: A 6-Year-Old Boy was Injured when a Motorbike Ran over his Foot. He Could not Put Weight and Had a Diffuse Painful Swelling,
Tenderness and Bruising of the Left Foot. Foot Radiographs (Top) were Initially Ordered in the Emergency Department. Fractures of the Metatarsals were Diagnosed. During the Follow-Up, Radiographs of the Ankle (Bottom) Indicated the Missed Talar Neck Fracture as well as the Undisplaced Fracture of the Distal Tibial Metaphysis.

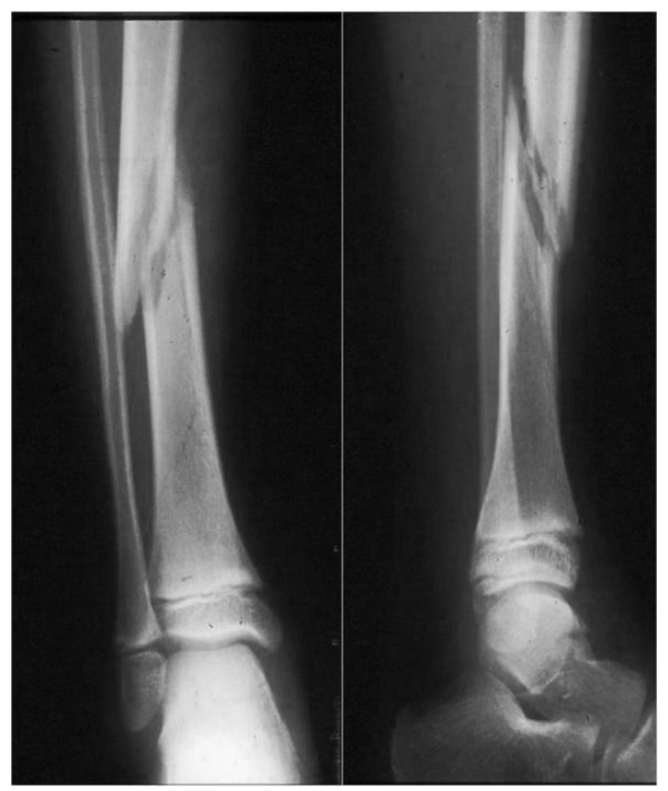

Figure 2: Radiographs of the Right Tibia and Ankle of a 9-Year-Old Boy after a Twisting Football Injury. Fracture of the Tibia was the Initial Diagnosis. The Talus Fracture was Missed in the Emergency Department.

Routine radiographic survey of talar fractures includes anteroposterior (AP), lateral, and oblique views centered over the hindfoot. Canale and Kelly have described an x-ray technique that optimizes viewing of the position of talar neck fractures in the AP plane. The view is obtained with the ankle plantar flexed, in 15 degrees of internal rotation, and with the x-ray beam directed 75 degrees cephalad from the table. Radiographs may not necessarily demonstrate a fracture or an osteochondral defect. Advanced imaging is often necessary to better characterize the fracture pattern or extent of injury. When no fracture is visualized on plain films and suspicion is high, based on the clinical examination, computed tomography (CT) or magnetic resonance imaging (MRI) is useful to identify an undisplaced or minimally displaced fracture. In the case of a comminuted fracture, CT may better delineate the fracture fragments, the degree of displacement and assist in determining the need for operative intervention. The edema pattern seen on MRI may also be helpful to delineate the occult injury of bone bruising. 
It is important to note that talus fractures may also be associated with other ipsilateral fractures. Even in the setting of an obvious talus fracture, radiographs must be scrutinized to rule out additional injuries. The 'floating ankle' is an underappreciated pattern of injury that has been reported following violent trauma and/or blast injuries usually in military personnel. It is characterized by an intact ankle mortise with a distal tibia fracture and an ipsilateral foot fracture, creating instability around the ankle. Talar neck fractures have also been described in children in association with compression injuries of the calcaneocuboid joint, as well as with fractures of the cuboid, with a combined transtalar/transcuboidal Chopart fracture disloc ation and fractures of the distal tibia.

Treatment of talar fractures in children largely depends on the age of the child and the amount of fracture displacement. Children with undisplaced or minimally displaced fractures are treated conservatively, with cast immobilization. In displaced fractures the principals of joint fractures should be followed to achieve an early anatomical reconstruction. Following reduction, whenever stability is questionable fixation is indicated. The approach is based on the fracture pattern and the need for both open reduction and fixation versus closed reduction and fixation. Reduction of talar neck fractures may be performed through a dorsomedial approach and fixation placed through a posterior approach. Tourniquet application may be a further negative factor for blood supply and may contribute to subsequent osteonecrosis. Due to the concern for the development of avascular necrosis, patients should be followed with serial radiographs. Nondisplaced fractures should be followed for at least 18 months and more severe fracture patterns followed well beyond this timeline. Considering the remodeling potential of the child's talus, less harm may be done by accepting minor displacement with a closed reduction than by potentially attenuating the blood supply through repeated manipulation or extensive open reduction.

Ischemic post-traumatic damage is the most serious complication after a talar fracture and is directly related to the extent of chondro-osseous transformation that has occurred at the time of injury. The less ossified structures are more resistant to permanent damage and have a better chance of remodeling. Osteonecrosis is the primary reason for any long-term disability after a fracture or dislocation of the talus. It usually develops between several weeks to 6 months after injury. Talar avascular necrosis may lead to post-traumatic arthritis. The incidence of avascular necrosis in children with undisplaced talus fractures may be up to $16 \%$, which is considerably higher than the reported in adults. However, this reported incidence could be due to initially missed and therefore non-treated fractures. Though it has not been proved, when avascular necrosis has been diagnosed and fracture healing has occurred, restriction of bearing weight is recommended in an effort to prevent collapse. The Hawkins sign, appearing 6-8 weeks post-injury, as radiolucency in the subchondral area of the talar body indicates a good blood supply or sufficient revascularization of the talus. Absence of the Hawkins sign is not considered an entirely reliable indicator that avascular necrosis will develop. Other complications associated with talus fractures include non-union, malunion, loose bodies, infection, neuropraxia and wound healing issues.

\section{REFERENCES}

[1] McKeever F. Fracture of the neck of the astragalus. Arch Surg. 1943; 46: 720-735.

[2] Blount WL. Fractures in children. Baltimore, Williams and Wilkins; 1955.

[3] Stephens NA. Fracture-dislocation of the talus in childhood; a report of two cases. Br J Surg. 1956; 43(182): 600- 604. PMID: 13342422.

[4] Hawkins LG. Fractures of the neck of the talus. J Bone Joint Surg Am. 1970; 52(5): 991-1002. PMID: 5479485.

[5] Sharrard WJW. Paediatric orthopaedics and fractures. Oxford, Blackwell; 1971.

[6] Sneppen O, Christensen SB, Krogsoe O, Lorentzen J. Fracture of the body of the talus. Acta Orthop Scand. 1977; 48(3): 317-324. PMID: 920125.

[7] Canale ST, Kelly FB. Fractures of the neck of the talus. Long-term evaluation of seventy-one cases. J Bone Joint Surg Am. 1978; 60(2): 143156. PMID: 417084.

[8] Letts RM, Gibeault D. Fractures of the neck of the talus in children. Foot Ankle. 1980; 1(2): 74-77. PMID: 7274901.

[9] Rang M. Children's fractures, 2nd Ed. Philadelphia, JB Lippincott; 1983.

[10] Schwarz N, Gebauer M. Fractures of the talus in children. Unfallheilkunde. 1983; 86: 212221.

[11] Mazel C, Rigault P, Padovani JP, Finidori G, Touzet P. Fractures of the talus in children. Apropos of 23 cases. Rev Chir Orthop 
Reparatrice Appar Mot. 1986; 72(3): 183-95. PMID: 3749552.

[12] Zwipp H, Ranft T. Malunited juvenile fractures in the foot region. Orthopäde. 1991; 20(6): 374-380.

[13] Stutz JM, Karlin JM, Daly N. Fracturedislocation of the talus in the pediatric patient. An unusual injury. J Am Podiatr Med Assoc. 1991; 81(9): 495-498. PMID: 1748966. DOI: 10.7547/87507315-81-9-495.

[14] Letts RM. Management of pediatric fractures. New York, Churchill Livingstone; 1994.

[15] Benson MKD, Fixsen JA, Macnicol MF. Children's orthopaedics and fractures. London, Churchill Livingstone; 1994.

[16] Jensen I, Wester JU, Rasmussen F, Lindequist S, Schantz K. Prognosis of fracture of the talus in children. 21 (7-34)-year follow-up of 14 cases. Acta Orthop Scand. 1994; 65(4): 398400. PMID: 7976283.

[17] Draijer F, Havemann D, Bielstein D. Injury analysis of pediatric talus fractures. Unfallchirurg. 1995; 98(3): 130-132. PMID: 7754399.

[18] Pereles TR, Koval KJ, Feldman DS. Fracturedislocation of the neck of the talus in a tenyear-old child: a case report and review of the literature. Bull Hosp Jt Dis. 1996; 55(2): 88-91. PMID: 8879745.

[19] Ogden JA. Skeletal injury in the child, 3rd Ed. New York, Springer-Verlag; 2000.

[20] Talkhani IS, Reidy D, Fogarty EE, Dowling FE, Moore DP. Avascular necrosis of the talus after a minimally displaced neck of talus fracture in a 6 year old child. Injury. 2000; 31(1): 63-65. PMID: 10716054.

[21] Rammelt S, Zwipp H, Gavlik JM. Avascular necrosis after minimally displaced talus fracture in a child. Foot ankle Int. 2000; 21(12): 10301036. PMID: 11139033.

[22] Leibner ED, Simanovsky N, Abu-Sneinah K, Nyska M, Porat S. Fractures of the lateral process of the talus in children. J Pediatr Orthop B. 2001; 10(1): 68-72. PMID: 11269815 .

[23] Paterson JM. Children's fractures 'not to be missed'. Hosp Med. 2002; 63(7): 426-428. PMID: 12187604.

[24] Judd DB, Kim DH. Foot fractures frequently misdiagnosed as ankle sprains. Am Fam Physician. 2002; 66(5): 785-794. PMID: 12322769.

[25] Nenopoulos SP, Papavasiliou VA, Papavasiliou A V. Talus fracture associated with a fracture dislocation of the distal tibia in an immature skeleton. Acta Orthop Belg. 2003; 69(5): 473475. PMID: 14648961.
[26] Von Laer L. Pediatric fractures and dislocations. New York, Georg Thieme Verlag; 2004.

[27] Prasad KSRK. Avascular necrosis of the talus after a minimally displaced neck of talus fracture in a 6-year-old child [Injury 31 (2000) 63-65]. Is it really unique? Injury. 2004; 35(11): 1216-1217. PMID: 15488523. DOI: 10.1016/j.injury.2004.02.016.

[28] Ribbans WJ, Natarajan R, Alavala S. Pediatric foot fractures. Clin Orthop Relat Res. 2005; 432: 107-115. PMID: 15738810.

[29] Meier R, Krettek C, Griensven M, Chawda M, Thermann H. Fractures of the talus in the pediatric patient. Foot Ankle Surg. 2005; 11: 510. DOI:10.1016/j.fas.2004.10.001.

[30] Jarvis JG, Paul J. Moroz PJ. Fractures and dislocations of the foot. In: Beaty JH, Kasser JR. Rockwood \& Wilkins' Fractures in Children, 6th Ed. Lippincott Williams \& Wilkins, 2006.

[31] Polyzois VD, Vasiliadis E, Zgonis T, Ayazi A, Gkiokas A, Beris AE. Pediatric fractures of the foot and ankle. Clin Podiatr Med Surg. 2006; 23(2): 241-55, v. PMID: 16903152.

[32] Gehr J, Friedl W. Fracture of the neck of the talus in a child. Unfallchirurg. 2006; 109(10): 910-913. PMID: $16944078 . \quad$ DOI: 10.1007/s00113-006-1128-z.

[33] Herring JA. Tachdjian's pediatric orthopaedics, 4th Ed. Philadelphia, Saunders Elsevier; 2008.

[34] Cartwright-Terry M, Pullen H. Non-operative management of a talar body fracture in a skeletally immature patient. Acta Orthop Belg. 2008; 74(1): 137-140. PMID: 18411617.

[35] Memisoglu K, Hürmeydan A. Total extrusion of the talus in an adolescent: a case report. J Am Podiatr Med Assoc. 2009; 99(5): 431-434. PMID: 19767550

[36] Eberl R, Singer G, Schalamon J, Hausbrandt P, Hoellwarth ME. Fractures of the talusdifferences between children and adolescents. J Trauma. 2010; 68(1): 126-130. PMID: $20065767 . \quad$ DOI: 10.1097/TA.0b013e3181a74667.

[37] Yazdi H, Ramezan Shirazi M. An unusual presentation of talus fracture in a child: a case report. Foot Ankle Surg. 2010; 16(3): e57-e60. PMID: 20655001. DOI: 10.1016/j.fas.2010.03.005.

[38] Smith JT, Curtis TA, Spencer S, Kasser JR, Mahan ST. Complications of talus fractures in children. J Pediatr Orthop. 2010; 30(8): 779784. PMID: 21102201. DOI: 10.1097/BPO.0b013e3181f73e6e.

[39] Byrne AM, Stephens M. Paediatric talus fracture. BMJ Case Rep. 2012; 2012. pii: bcr1020115028. PMID: 22605852. PMCID: PMC3351635. DOI: 10.1136/bcr.10.2011.5028. 
[40] Godoy-Santos AL, Albuquerque DM, DinizFernandes T, Rammelt S. Fracture of the talar neck associated with a compression fracture of the calcaneocuboid joint in a 5-year-old child: a case report. Arch Orthop Trauma Surg. 2013; 133(9): 1267-1271. PMID: 23784318. DOI: 10.1007/s00402-013-1791-9.

[41] Prasad KSRK, Vali H, Hussain A. Hawkins group I fracture of neck of talus and Salter Harris Type III tibial epiphyseal injury of medial malleolus. Foot (Edinb). 2013; 23(2-3): 96-99. PMID: 23639364. DOI: 10.1016/j.foot.2013.03.002.

[42] Sferopoulos NK. Residual symptoms of occult pediatric ankle injuries: MRI-diagnosed bone bruising. British Journal of Medicine \& Medical Research 2014; 4(1): 295-303. DOI: 10.9734/BJMMR/2014/5607.

[43] Jindal N, Gupta P, Jindal S. Nonunion of paediatric talar neck fracture. Chin J Traumatol. 2014; 17(1): 48-49. PMID: 24506925.

[44] Patel V, Bloch B, Johnson N, Mangwani J. Delayed presentation of a loose body in undisplaced paediatric talar neck fracture. World J Orthop. 2014; 5(3): 398-401. PMID: 25035846. PMCID: PMC4095036. DOI: 10.5312/wjo.v5.i3.398.

[45] Inal S, Inal C. A pediatric comminuted talar fracture treated by minimal K-wire fixation without using a tourniquet. Iowa Orthop J. 2014; 34: 175-180. PMID: 25328479. PMCID: PMC4127733.

[46] Crosswell S, Rhee SJ, Wagner WW. Unusual fracture combination in a paediatric acute ankle (combined medial talar compression fracture with medial malleolus fracture in an immature skeleton): a case report. J Surg Case Rep. 2014; 2014(10). pii: rju100. PMID: 25320236. PMCID: $\quad$ PMC4197413. DOI: 10.1093/jscr/rju100.

[47] Kamphuis SJ, Meijs CM, Kleinveld S, Diekerhof $\mathrm{CH}$, van der Heijden FH. Talar fractures in children: A possible injury after gokarting accidents. J Foot Ankle Surg. 2015; 54(6): 1206-1212. PMID: 26364700. DOI: 10.1053/j.jfas.2015.07.013.

[48] Melenevsky Y, Mackey RA, Abrahams RB, Thomson NB 3rd. Talar fractures and dislocations: A radiologist's guide to timely diagnosis and classification. Radiographics.
2015; 35(3): 765-779. PMID: 25969933. DOI: 10.1148/rg.2015140156.

[49] Sferopoulos NK. The classification of physeal injuries. ARC Journal of Orthopedics 2016; 1(1): 23-27. DOI: http://dx.doi.org/10.20431/2456-0588.0101005.

[50] Sferopoulos NK. Segmental forearm bone injuries in children: classification and treatment. J Orthop Traumatol. 2016; 17(3): 215-221. PMID: 26861759. PMCID: PMC4999371. DOI: 10.1007/s10195-0150389-0.

[51] Wu Y, Jiang H, Wang B, Miao W. Fracture of the lateral process of the talus in children: A kind of ankle injury with frequently missed diagnosis. J Pediatr Orthop. 2016; 36(3): 289293. PMID: $25785595 . \quad$ DOI: 10.1097/BPO.0000000000000437.

[52] Rammelt S, Godoy-Santos AL, Schneiders W, Fitze G, Zwipp H. Foot and ankle fractures during childhood: review of the literature and scientific evidence for appropriate treatment. Rev Bras Ortop. 2016; 51(6): 630-639. PMID: 28050532. PMCID: PMC5198067. DOI: 10.1016/j.rboe.2016.09.001.

[53] Michel-Traverso A, Ngo TH, Bruyere C, Saglini M. Talus fracture in a 4-year-old child. BMJ Case Rep. 2017; 2017. pii: bcr-2016215063. PMID: 28400423. PMCID: PMC5534889. DOI: 10.1136/bcr-2016-215063.

[54] Kothadia S, Birole U, Ranade A. Paediatric Salter-Harris type IV injury of distal tibia with talus fracture. BMJ Case Rep. 2017; 2017. pii: bcr-2017-222226. PMID: 29183896. DOI: 10.1136/bcr-2017-222226.

[55] K1zılay YO, Aytan O. Low-energy Hawkins type III talar neck fracture-dislocation with neurovascular and tendon entrapment in a pediatric patient. J Foot Ankle Surg. 2017; 56(6): 1288-1291. PMID: 28778631. DOI: 10.1053/j.jfas.2017.05.007.

[56] Hood CR Jr, Miller JR, Hollinger JK. Defining talar head and neck pathology: The Malvern classification system. J Foot Ankle Surg. 2017; pii: S1067-2516(17)30455-6. PMID: 28843549. DOI: $10.1053 /$ j.jfas.2017.07.008.

[57] Sferopoulos NK. Talus fractures in children. ARC Journal of Research in Sports Medicine. 2017; 2(1): 21-26.

Citation: N. K. Sferopoulos. Talus Fractures in Children Associated with Ipsilateral Bone Injuries. ARC Journal of Orthopedics. 2017; 2(2):1-5. doi:dx.doi.org/ 10.20431/2456-0588.0202001.

Copyright: (C) 2017 Authors. This is an open-access article distributed under the terms of the Creative Commons Attribution License, which permits unrestricted use, distribution, and reproduction in any medium, provided the original author and source are credited. 